\title{
Las bases de la exitosa adaptación de Eroski a las nuevas condiciones del mercado
}

\author{
Enrique Gadea \\ Universidad de Deusto
}

Sumario: I. Introducción. II. El nuevo modelo: 2.1. La dimensión. 2.2. La estructura societaria. 2.3. La eficacia organizativa. 2.4. La rentabilidad. 2.5. La financiación. 2.6. Aspectos laborales y reparto de beneficios. 2.7. La defensa del consumidor.

Resumen: En este trabajo se abordan de forma esquemática los parámetros sobre los que debe sustentarse una cooperativa de consumo moderna sobre las bases trazadas por el Grupo Eroski.

Palabras clave: cooperativas de consumo y mercado

Abstract: This article offers a schematic approach to the parameters according to which a modern consumer cooperative should be formed, according to the bases set by the Eroski Group.

Key words: consumer cooperatives and markets. 


\section{Introducción}

Después de unos años precedentes de niveles de ventas generales aceptables, la situación de las cooperativas de consumo en España comienza a debilitarse en la década de los setenta. Posiblemente, una de las causas del descenso de su cuota de mercado fue la aparición de los primeros autoservicios y supermercados, aunque también es indudable que las propias cooperativas tenían que hacer frente a problemas internos que amenazaban su propio funcionamiento. Entre ellos, cabe destacar: el coste de un personal, numeroso y poco preparado para asumir las nuevas exigencias del mercado y la existencia de unas instalaciones desfasadas, que no eran sólo poco atractivas sino insuficientes para vender nuevos productos. A ello debe añadirse los problemas de liquidez, a causa del pago aplazado por medio de las tradicionales libretas y de la política de distribución de retornos motivada por la presión de los socios, y los derivados de la pequeña dimensión de muchas de las cooperativas de consumo existentes. Dada la situación, la alternativa era clara: adaptación o cierre de puertas.

\section{El nuevo modelo}

Una de las adaptaciones más exitosas es la del Grupo Eroski. La adaptación de Eroski se basa en dos premisas fundamentales: por una parte, en la aceptación del principio de que la rentabilidad está en vender muchos productos con unos márgenes más reducidos, y, por otra, en que era necesario crear una organización en la que tanto consumidores como trabajadores fueran la esencia del modelo. Lo que Eroski pretendía era componer unos órganos de decisión paritaria con representantes de los intereses de los consumidores y de los trabajadores.

Las bases sobre las que se sustenta la entidad cooperativa se centran en los siguientes aspectos: la dimensión, la estructura societaria, la eficacia organizativa, la rentabilidad, la financiación y la defensa del consumidor.

\subsection{La dimensión}

El tamaño constituye un factor importante para determinar la capacidad competitiva de las empresas en la mayoría de los sectores económicos y, de manera especial, dentro del sector de la distribución. 
Ser competitivos demanda una dimensión mínima difícil de determinar, pero que en todo caso reclama una posición dentro del grupo de las diez primeras empresas de la distribución. Quedarse fuera de ese grupo supone aceptar una posición de marginalidad, con el consiguiente deterioro de la presencia cooperativa en el mercado.

De todo ello se deduce que, allí donde aún sea posible, deberían instrumentarse procesos de fusión que condujeran a una dirección estratégica unificada para el conjunto de España, que a su vez permitiera acuerdos con las cooperativas de otros países, al menos en el ámbito de la Comunidad Europea.

\subsection{La estructura societaria}

Debe revisarse el papel de los trabajadores que prestan su servicio en la cooperativa de consumo. Consumidor y trabajador son los dos protagonistas de todo fenómeno económico Esta idea debe quedar reflejada en la estructura mediante la constitución de órganos: Consejo Rector y Asamblea General, en la que los dos colectivos estén representados adecuadamente, apostando a este respecto por una composición paritaria.

\subsection{Eficacia organizativa}

Históricamente, las cooperativas han tenido siempre dificultades o reticencias para dotarse de un equipo de ejecutivos capaces de realizar una gestión técnica de su empresa al nivel de sus competidoras. A mediados de la década de los noventa resulta evidente la necesidad de resolver esa carencia, ya que si algo caracteriza al sector en el que las cooperativas de consumo desarrollan su actividad económica, es la competitividad creciente entre empresas cada vez más organizadas y de mayor tamaño.

Encontrar dentro de ese mercado una capacidad de dirección de la cooperativa acorde a las necesidades empresariales que se plantean ya no puede suplirse mediante esfuerzos voluntaristas. Si algún papel le está reservado todavía al cooperativismo, pasa por lograr equipos ejecutivos altamente cualificados, intentando simultáneamente que además sean buenos cooperativistas. 


\subsection{Rentabilidad}

Todo el modelo debe estar orientado hacia la rentabilidad. Aunque no lo parezca, el hecho de que aún sea posible encontrarse con cooperativas y con teóricos del cooperativismo que piensan que el beneficio no es un objetivo, es más que preocupante.

Debe reivindicarse el beneficio, no sólo como algo conveniente, sino como un objetivo insoslayable de las cooperativas de consumo. Lo que debe diferenciar a una cooperativa de una empresa capitalista no es, en ningún caso, la ausencia de beneficios, sino el destino que se dé a los mismos, es decir, su distribución.

La generación de riqueza es algo fundamental en cualquier proyecto económico, ya que a través de la misma se garantiza el desarrollo del modelo, cooperando además a través de la inversión a la creación de empleo. En la disyuntiva que suele plantearse entre la obtención de beneficios o la disminución de los precios de los productos, se esconde un falso problema porque, a largo plazo, sólo una cooperativa con beneficios podrá tener buenos precios.

Por otra parte, una distribución individual de los recursos, mediante un ajuste a la baja de los precios, es menos eficaz que la utilización de estos recursos acumulados a través de la cooperativa. Resulta mucho más coherente con la filosofía cooperativa, la suma de recursos individuales para la realización de proyectos colectivos, que su distribución para consumo de forma personalizada.

En todo caso, fuesen cuales fueran los criterios utilizados en la distribución de los resultados, estos no deben salir de la cooperativa e, incluso, en el caso de que se distribuyeran retornos a los trabajadores, estos deberían ser capitalizados.

\subsection{Financiación}

Un modelo de cooperativa adaptado a las exigencias del mercado requiere de importantes recursos financieros que no pueden limitarse a la capacidad de generación interna. Más, si se tiene en cuenta que las cooperativas de consumo española arrancan con un retraso importante, y que actualmente el mercado se encuentra bien dotado de estructuras comerciales explotadas por empresas consolidadas y dinámicas.

Estar presentes en ese mercado requerirá abordar fórmulas comerciales capaces de competir, al menos, en igualdad de circunstancias; lo cual exigirá la disponibilidad de importantes cantidades financieras. La 
capacidad del consumidor para proveer los recursos necesarios es muy limitada, por lo que habrá que recurrir a otras fuentes alternativas. El recurso a la banca es probablemente la vía más aceptable, si bien hay que tener en cuenta la escasa fiabilidad que la misma ha concedido históricamente a los proyectos cooperativos.

En otro orden de cosas, Eroski asumió desde un principio su naturaleza de cooperativa de consumo, por lo que integró el consumerismo en su gestión empresarial, comprometiéndose siempre con la formación y defensa de los consumidores, como guía de su acción empresarial. Desde el punto de vista cultural, Eroski incorporó una nueva perspectiva en su concepto de aportación a la comunidad, y consciente de cuáles son sus raíces, esta cooperativa se caracterizó por su voluntad de invertir en el desarrollo de su entorno, apoyando siempre las pequeñas iniciativas populares de carácter socio-cultural, frente a otras opciones más espectaculares.

\subsection{Aspectos laborales y reparto de beneficios}

En Eroski no existen los sindicatos porque son los trabajadores, junto con los consumidores, los que toman las decisiones de gobierno de la empresa. Eroski, contempla un nuevo concepto en el reparto de los beneficios. Así, el $50 \%$ de estos se destina a un capítulo de reservas, que tienen por objeto reforzar los fondos de la cooperativa -unos fondos que no pueden ser repartidos, ni aún en el caso de disolución de la sociedad-; otro $40 \%$, es devuelto a los socios en forma de retorno cooperativo, que queda capitalizado en la cooperativa, y que el socio sólo podrá percibir en el momento en que se desvincule de ésta. El restante $10 \%$ del beneficio se destina, principalmente, a financiar actividades consumeristas, encaminadas a informar y formar al propio consumidor, de forma que éste pueda tomar decisiones con más información. Como consecuencia de esta filosofía nace el Departamento de Consumo de Eroski, constituido por un equipo de profesionales especialistas en las distintas áreas que abarca el consumo, cuyo objetivo es contribuir a mejorar la capacidad decisoria de los consumidores. Para dar respuesta a los objetivos marcados, este Departamento diseña y desarrolla diferentes actividades formativas y edita diversas publicaciones orientadas a informar y formar al consumidor. Al mismo tiempo, el Departamento de Consumo participa en los distintos órganos de representación de los propios consumidores en instancias autonómicas, estatales y europeas. 


\subsection{La defensa del consumidor}

Esta nueva función que ofrece la cooperativa al consumidor tiene además un doble objetivo. No se trata sólo de dar la oportunidad al cliente de que opine sobre el producto que se oferta. Es decir, Eroski no sólo atiende las reclamaciones y sugerencias, sino que además está dotada y concebida para actuar en consecuencia, ofreciendo al consumidor lo que éste demande. Por tanto, a partir de la demanda y planteamiento del consumidor, Eroski orienta su oferta. Por primera vez, una organización de consumidores y una empresa distribuidora forman parte de un mismo proyecto, que contribuye a dar sentido y a justificar la existencia y el adecuado tratamiento, incluso en el orden fiscal, de la formula cooperativa. 